\title{
First Test of an Automated Detection Platform to Identify Risk of Decompensation in Elderly Patients
}

\author{
Abrar-Ahmad Zulfiqar $^{1}$, Orianne Vaudelle ${ }^{2}$, Mohamed Hajjam², Dominique Letourneau ${ }^{3}$, Jawad Hajjam ${ }^{4}$, Sylvie Erve ${ }^{4}$, \\ Anna Karen Garate Escamilla ${ }^{5}$, Amir Hajjam ${ }^{5}$, Emmanuel Andres ${ }^{1}$ \\ ${ }^{1}$ Service de Médecine Interne, Diabète et Maladies Métaboliques de la Clinique Médicale B, Hôpitaux Universitaires de Strasbourg and Equipe EA 3072 \\ "Mitochondrie, Stress oxydant et Protection musculaire", Faculté de Médecine, Université de Strasbourg, Strasbourg, France \\ ${ }^{2}$ Predimed Technology, Schiltigheim, France \\ ${ }^{3}$ Fondation de l'Avenir pour la Recherche Médicale Appliquée, Paris, France \\ ${ }^{4}$ Centre d'Expertise des TIC pour l'autonomie (CenTich) et Mutualité Française Anjou-Mayenne (MFAM) - Angers, Angers, France \\ ${ }^{5}$ Laboratoire IRTES-SeT, Université de Technologie de Belfort-Montbéliard (UTBM), Belfort-Montbéliard, Belfort, France
}

Received: $27 / 10 / 2020$

Accepted: $28 / 10 / 2020$

Published: $10 / 12 / 2020$

How to cite this article: Zulfiqar AA, Vaudelle O, Hajjam M, Letourneau D, Hajjam J, Erve S, Garate Escamilla AK, Hajjam A, Andres E. First test of an automated detection platform to identify risk of decompensation in elderly patients. EJCRIM 2020;7: doi:10.12890/2020_002102.

Conflicts of Interests: Mohamed Hajjam is CEO of Predimed Technology. The other authors declare there are no competing interests.

This article is licensed under a Commons Attribution Non-Commercial 4.0 License

\section{ABSTRACT}

Introduction: We tested the MyPredi ${ }^{\mathrm{TM}}$ e-platform which is dedicated to the automated, intelligent detection of situations posing a risk of decompensation in geriatric patients.

Objective: The goal was to validate the technological choices, to consolidate the system and to test the robustness of the MyPredi ${ }^{\mathrm{TM}}$ e-platform through daily use.

Results: The telemedicine solution took 3,552 measurements for a hospitalized patient during her stay, with an average of 237 measurements per day, and issued 32 alerts, with an average of 2 alerts per day. The main risk was heart failure which generated the most alerts ( $n=13$ ). The platform had $100 \%$ sensitivity for all geriatric risks, and had very satisfactory positive and negative predictive values.

Conclusion: The present experiment validates the technological choices, the tools and the solutions developed.

\section{LEARNING POINTS}

- Patients with chronic conditions can be monitored with telemedicine systems to optimise their management, particularly during the COVID-19 pandemic.

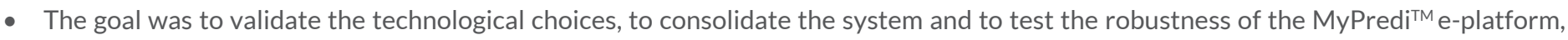
through daily use in an elderly patient.

- The present experiment demonstrates the relevance of the technological choices, the tools and the solutions developed.

\section{KEYWORDS}

Telemonitoring, geriatric risks, MyPredi ${ }^{\mathrm{TM}}$ e-platform, GER-e-TEC study 


\section{INTRODUCTION}

Telemedicine can be used to optimise the management of elderly patients with chronic conditions. Such systems can decrease morbidity and mortality, reduce re-hospitalization, improve quality of life, and lower medical and economic costs ${ }^{[1]}$.

This was the basis for the "GERIATRICS and e-Technology (GER-e-TEC) study", which was an experiment involving the use of the smart MyPredi ${ }^{\mathrm{TM}}$ e-platform to automatically detect the exacerbation of geriatric syndromes.

\section{METHODS}

A tablet and connected devices were used to measure patient blood pressure, heart rate, weight, oxygen saturation, capillary blood glucose, temperature and physical activity. The technical characteristics of the sensors are detailed in Table 1. The device has ISO13485 medical certification and CE marking ${ }^{[2]}$.

Wegathered information on events common in the geriatric population (falls, constipation, dehydration, confusion, iatrogenism, malnutrition, heart failure, diabetes, infections and bedsores) by means of (a) questionnaires at patient inclusion and during their hospital stay and (b) regular questionnaires during follow-up (Table 2)

\begin{tabular}{|c|c|c|}
\hline Geriatric risk & Connected Sensors/Questionnaires & Frequency \\
\hline $\begin{array}{l}\text { Hemodynamic data } \\
\text { (hypertension/hypotension-tachycardia/ } \\
\text { bradycardia-oxygen desaturation/ } \\
\text { infections) }\end{array}$ & $\begin{array}{l}\text { Sphygmomanometer-pulse } \\
\text { oximeter-thermometer }\end{array}$ & Three times per day \\
\hline Heart failure & Questionnaire & Daily \\
\hline Constipation & Questionnaire & Twice a day \\
\hline Risk of bed rest & $\begin{array}{l}\text { Questionnaire } \\
\text { Pedometer }\end{array}$ & $\begin{array}{l}\text { Daily } \\
\text { Daily }\end{array}$ \\
\hline Pain & Questionnaire & Daily \\
\hline Dehydration & $\begin{array}{l}\text { Questionnaire } \\
\text { Biological sensors (natremia-kaliemia-creatinine) }\end{array}$ & $\begin{array}{l}\text { Daily } \\
\text { Twice a week }\end{array}$ \\
\hline Sleep quality & Pedometer & Day and night \\
\hline Physical activity & $\begin{array}{l}\text { Pedometer } \\
\text { Questionnaire }\end{array}$ & $\begin{array}{l}\text { Daily } \\
\text { Daily }\end{array}$ \\
\hline Diabetes & Glucometer & Three times per day \\
\hline latrogenism & Questionnaire & $\begin{array}{l}\text { On admission and } \\
\text { once during hospitalization }\end{array}$ \\
\hline Malnutrition & $\begin{array}{l}\text { Balance } \\
\text { Biological sensor (albumin) }\end{array}$ & $\begin{array}{l}\text { Twice a week } \\
\text { Once during hospitalization }\end{array}$ \\
\hline
\end{tabular}

Table 1. Remote monitoring of geriatric risks in the GER-e-TEC study

\begin{tabular}{|l|l|}
\hline Geriatric risk & Alerts $(\boldsymbol{n})$ \\
\hline Heart failure & 13 \\
\hline Pain & 4 \\
\hline Dehydration & 7 \\
\hline latrogenism & 3 \\
\hline Malnutrition & 0 \\
\hline Constipation & 0 \\
\hline Risk of being bedridden & 5 \\
\hline
\end{tabular}

Table 2. Number of alerts and recommendations by geriatric risk 


\section{RESULTS}

A 73-year-old female patient was admitted to the Emergency Department for the management of bronchial pneumonia. Written consent was obtained for inclusion in the study.

Her medical history included stage 3 COPD (under $1 \mathrm{I}$ of oxygen at home), high blood pressure, dyslipidaemia, an episode of gout and thyroidectomy. Her Charlson's Comorbidity Index score was 4. Usual treatment included L-thyroxine $100 \mu \mathrm{g}$ daily, candesartan $8 \mathrm{mg}$ once daily, allopurinol $100 \mathrm{mg}$ once daily, atorvastatin $40 \mathrm{mg}$ once daily, bisoprolol $2.5 \mathrm{mg}$ once daily, acetylsalicylic acid $75 \mathrm{mg}$ once daily and furosemide $40 \mathrm{mg}$ once daily. She was independent and lived at home with her daughter with no other assistance.

The patient received telemonitoring surveillance throughout her 17-day hospital stay. Figure 1 shows some screen shots from the MyPredi ${ }^{\top M}$ e-platform remote monitoring system.

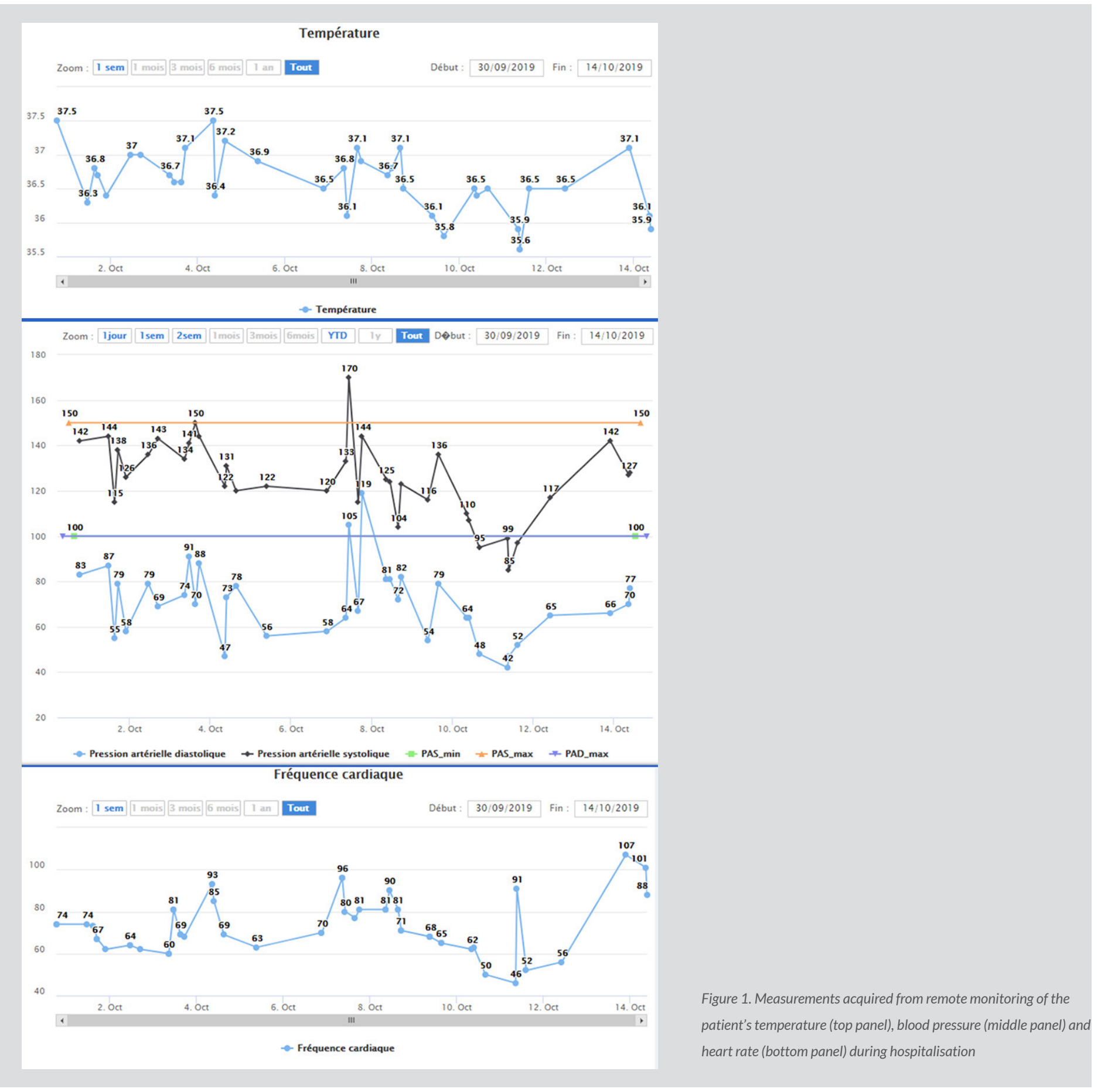


Mean blood pressure was $104.70 \pm 10.16 \mathrm{mmHg}$, mean heart rate was $72.9 \pm 13.1 \mathrm{bpm}$, and mean oxygen saturation was $94.2 \pm 1.4 \%$. Mean activity was $751.6 \pm 323.6$ steps per day with a median of 806 . Mean sleep per day was $455 \pm 133.7$ min with a median of 512 min. Mean light sleep was $81.8 \pm 43$ minutes with a median of 87 minutes, and mean deep sleep was $373.2 \pm 105.8$ min with a median of 398 min. The mean pain VAS (visual analogue scale) was $1.4 \pm 2$. The mean pain EVS (simple verbal scale) was $0.7 \pm 0.8$ with a median of 0 . Mean weight was 109.7 $\mathrm{kg}$. The mean number of stools was $0.6 \pm 0.6$ stools per day, and mean temperature was $36.6 \pm 0.5^{\circ} \mathrm{C}$. The patient answered only two of the nine bedrest questionnaires administered.

The telemedicine system took 3,552 measurements for the patient throughout her hospitalization, with an average of 237 per day, and issued 32 alerts with an average of 3 per day. There were 10 mild alerts, 4 moderate alerts, and 18 severe alerts. Heart failure risk generated the most alerts ( $\mathrm{n}=13$; Table 2).

Table 3 shows the sensitivity, specificity, positive predictive values and negative predictive values of the alerts for the criteria studied.

\begin{tabular}{|l|l|l|l|l|l|l|l|}
\hline & Heart failure & Pain & Dehydration & Constipation & $\begin{array}{l}\text { Risk of } \\
\text { becoming } \\
\text { bedridden }\end{array}$ & Malnutrition & Iatrogenism \\
\hline Sensitivity & $100 \%$ & $100 \%$ & $100 \%$ & - & $100 \%$ & - & $100 \%$ \\
\hline Specificity & - & - & $50 \%$ & $50 \%$ & & $40 \%$ & $44 \%$ \\
\hline $\begin{array}{l}\text { Positive } \\
\text { predictive value }\end{array}$ & $100 \%$ & $100 \%$ & $40 \%$ & - & $100 \%$ & - & $23 \%$ \\
\hline $\begin{array}{l}\text { Negative } \\
\text { predictive value }\end{array}$ & - & - & $100 \%$ & $100 \%$ & - & $100 \%$ & $100 \%$ \\
\hline
\end{tabular}

Table 3. Sensitivity, specificity, positive and negative predictive values of alerts from the MyPrediT ${ }^{\mathrm{T}}$ e-platform monitoring system

\section{DISCUSSION}

Our innovative telemedicine solution enables remote monitoring of geriatric patients through the use of non-intrusive medical sensors that allow the patient's physiological data to be fed back to healthcare professionals. It also includes questionnaires integrated into the MyPredi ${ }^{\mathrm{TM}}$ e-platform. Previous work described in the literature has focused primarily on the risk of falling ${ }^{[3,4]}$ and the monitoring of neuropsycho-behavioural disorders ${ }^{[5]}$. Our telemonitoring project will allow us to comprehensively assess elderly patients. The project proposes personalized medical follow-up to prevent acute decompensation via the MyPredi ${ }^{\mathrm{TM}}$ e-platform telemonitoring platform, which allows for the early detection of situations posing a risk of deterioration in the patient's health status by sending alerts to healthcare professionals. Daily medical monitoring of patients, based on personalized protocols set up by the medical profession, can be carried out by healthcare teams on the MyPredi ${ }^{\mathrm{TM}}$ e-platform using measurements and online questionnaires. When a patient is at risk of deterioration, alerts are sent to a coordinating medical unit so measurements can then be taken.

These results show that the MyPredi ${ }^{\mathrm{TM}}$ e-platform telemedicine system automatically and non-intrusively generates alerts related to risk, particularly with regard to pain, immobility and heart failure; it showed high sensitivity and $100 \%$ positive predictive values for these three criteria. This experiment also demonstrated that the MyPredi ${ }^{\mathrm{TM}}$ e-platform system could detect other risks such as dehydration and iatrogenia. For the practitioner, this means that if no alert is received, then the patient does not require intervention (100\% negative predictive value). However, many false alarms can be generated due both to non-compliance with protocol and to likely over-sensitivity of the system.

\section{CONCLUSION}

After an experimental phase and following implementation of technological processes on the MyPredi ${ }^{\mathrm{T} M}$ e-platform, remote monitoring of 36 patients was carried out between 24 September 2019 and 24 November 2019. The results of this phase of telemonitoring of 10 geriatric risks will be released later. 


\section{REFERENCES}

1. Zulfiqar AA, El Hassani Hajjam A, Talha S, Hajjam M, Hajjam J, Ervé S, et al. Les expérimentations de télémédecine en établissement d'hébergement pour personnes âgées dépendantes en France: revue de la littérature. Médecine thérapeutique 2019;25(2):107-113.

2. Zulfiqar AA, Lorenzo-Villalba N, Zulfiqar OA, Hajjam M, Courbon Q, Esteoulle L, et al. e-Health: a future solution for optimized management of elderly patients. GER-e-TEC ${ }^{\text {TM }}$ Project. Medicines 2020;7:41.

3. Piau A, Mattek N, Crissey R, Beattie Z, Dodge H, Kaye J. When will my patient fall? Sensor-based in-home walking speed identifies future falls in older adults. J Gerontol A Biol Sci Med Sci 2020;75(5):968-973.

4. Vermeulen J, Neyens JC, Spreeuwenberg MD, van Rossum E, Boessen AB, Sipers W, et al. The relationship between balance measured with a modified bathroom scale and falls and disability in older adults: a 6-month follow-up study. J Med Internet Res 2015;17(5):e131.

5. Piau A, Lepage B, Bernon C, Gleizes MP, Nourhashemi F. Real-time detection of behavioral anomalies of older people using artificial intelligence (The 3-PEGASE Study): protocol for a real-life prospective trial. JMIR Res Protoc 2019;8(11):e14245. 